\title{
Survey of Virulence Determinants among Vancomycin Resistant Enterococcus faecalis and Enterococcus faecium Isolated from Clinical Specimens of Hospitalized Patients of North west of Iran
}

\author{
Yaeghob Sharifi ${ }^{1,2,6}$, Alka Hasani ${ }^{1,2, *}$, Reza Ghotaslou ${ }^{2}$, Mojtaba Varshochi ${ }^{1,3}$, Akbar Hasani ${ }^{1,4}$, \\ Mohammad Aghazadeh ${ }^{2}$ and Morteza Milani ${ }^{2,5}$
}

\author{
${ }^{1}$ Research Center of Infectious Diseases and Tropical Medicine, Tabriz University of Medical Sciences, Tabriz, Iran \\ ${ }^{2}$ Department of Clinical Microbiology, Faculty of Medicine, Tabriz University of Medical Sciences, Tabriz, Iran \\ ${ }^{3}$ Department of Infectious Diseases, Faculty of Medicine, Tabriz University of Medical Sciences, Tabriz, Iran \\ ${ }^{4}$ Department of Clinical Biochemistry and Biotechnology, Tabriz University of Medical Sciences, Tabriz, Iran \\ ${ }^{5}$ Faculty of Pharmacy, Faculty of Medicine, Tabriz University of Medical Sciences, Tabriz, Iran \\ ${ }^{6}$ Microbiology laboratory of Imam Khomeini Hospital, Orumieh University of Medical Sciences, Orumieh, Iran
}

\begin{abstract}
Recent data indicates an increasing rate of vancomycin resistance in clinical enterococcal isolates worldwide. The nosocomial enterococci are likely to harbor virulence elements that increase their ability to colonize hospitalized patients. The aim of this study was to characterize virulence determinants in vancomycin-resistant enterococci (VRE) obtained from various clinical sources.

During the years 2008 to 2010 , a total of 48 VRE isolates were obtained from three University teaching hospitals in Northwest, Iran. Initially, phenotypic speciation was done and minimum inhibitory concentrations (MICs) of vancomycin were determined by agar dilution method and E-test. Then, species identification and resistance genotypes along with detection of virulence genes ( $a s a 1$, esp, gelE, ace and $c p d$ ) of the isolates were performed by multiplex PCR.

Thirty eight isolates were identified as vancomycin-resistant Enterococcus faecium (VREfm) and ten as E. faecalis (VREfs). Irrespective of the species, vanA gene (89.58\%) was dominant and three phenotypically vancomycin susceptible E. faecium isolates carried the $v a n B$ gene. Among virulence genes investigated, the esp was found in 27(71\%) VREfm strains, but did not in any VREfs. Other virulence determinants were highly detected in VREfs strains. Our data indicate a high prevalence of E. faecium harboring vancomycin resistance with vanA genotype and the two VRE species displayed different virulence genes.
\end{abstract}

Keywords: Enterococcus faecalis, Enterococcus faecium, Vancomycin resistance, Virulence gene.

\section{INTRODUCTION}

Enterococci are Gram-positive intestinal commensals of humans and other animals, in addition to be an isolate from environmental sources. During the past decades an enhancement in the prevalence of enterococal infections such as bacteremia and urinary tract infections along with emergence of multi antimicrobial resistance, particularly VRE has been reported worldwide [1,2].

Among vancomycin-resistance phenotypes in enterococci, VanA and VanB possess highest clinical importance. Strains resistant to vancomycin and teicoplanin were assigned to

*Address correspondence to this author at the Research Center of Infectious Diseases and Tropical Medicine, and Department of Clinical Microbiology, Faculty of Medicine, Tabriz University of Medical Sciences, Tabriz, Iran; Tel: 00984113364661 ; Fax: 00984113364661

E-mails: hasanialka@tbzmed.ac.ir,dr.alkahasani@gmail.com
VanA phenotype while, those susceptible to teicoplanin but resistant to vancomycin were considered as the VanB phenotype [2]. The vanA and $v a n B$ gene clusters contain nine different genes for a two-component regulatory system (vanR and vanS), three resistance genes ( $v a n H$, encoding dehydrogenase; vanA or vanB, encoding ligase; vanX, encoding DD-dipeptidase); an accessory gene ( $\operatorname{van} Y$ ); and the vanZ gene, which is present in the vanA gene cluster whereas, the van $W$ gene is found only in the van $B$ operon. VanA is carried on Tn1546 whilst, VanB on transposons $\operatorname{Tn} 1547$ and $\operatorname{Tn} 1549$, which may be found on plasmids or inserted on the chromosome [3].

Despite the fact that $E$. faecalis has been observed as the predominant species in clinical infections, an increase in the prevalence of E. faecium has been seen recently [4]. This shift is likely to be explained in part by the emergence of vancomycin resistant enterococci (VRE) and E. faecium being the dominant detectable species among them [5]. 
Unfortunately, little is known about the pathogenic mechanisms or virulence factors of this microorganism [6]. Enterococcal infections may occur via the ability to persist on harsh environments due to their intrinsic properties and even these conditions may contribute largely to emergence of this organism as a nosocomial pathogen [7, 8]. The process of invasion is usually facilitated by damage to host tissues and the presence of bacterial virulence factors such as adhesins along with antibiotic resistance that gradually assist in advancement and furtive survival in newly infected place. At the next, enterococci utilize several virulence factors for adherence and colonization in the infection site by formation of cell aggregates such as biofilms [5, 9]. At the end, interactions between host and enterococci leads to the clinical manifestation of infection in target vital tissues [5].

By consideration of the fact that the presence of putative virulence determinants among clinical isolates may promote emergence of infections and persistence of enterococci in nosocomial locations causes an increase in antibiotic resistance and act as facilities for emerging infections [10, 11], this study was designed to survey distribution of virulence genes including asal(aggregation substance), esp (Enterococcal surface protein), gelE (gelatinase), ace (collagen adhesion) and cpd (sex pheromones determinant) in clinical isolates of vancomycin resistant E. faecalis and $E$. faecium at molecular level. To our knowledge, this is the first report from the Northwest of Iran.

\section{MATERIALS AND METHODOLOGY}

\section{VRE Isolates and Susceptibility Tests}

Thirty-eight VREfm and 10 VREfs isolates, obtained from different clinical specimens submitted in three
University teaching hospitals of Tabriz (Imam Reza and Sina Hospitals) and Orumieh (Imam Khomeini Hospital), Iran, between 2008 and 2010. The origins of isolates were as follows: urine $35(72.91 \%)$, blood $5(10.41 \%)$, wound $3(6.25 \%)$, body fluids $4(8.33 \%)$ and intravenous catheter $1(2.08 \%)$. Initially, these isolates were identified to the species level by conventional methods described previously [12] and then, multiplex PCR was used to detect vancomycin resistant vanA and $v a n B$ genes and also to confirm phenotypic speciation by targeting D-alanine- D-alanine ligases specific for $E$. faecalis $\left(d d l_{E \text {. faecalis }}\right)$ and $E$. faecium $\left(d d l_{E \text {. faecium }}\right)$ as developed by Kariyama et al., [13]. E. faecalis E206 (vanA ${ }^{+}$) and E. faecium E2781 (vanB ${ }^{+}$) (kindly provided by Dr. Eimaneini) was used as control strains.

For all isolates, MICs of vancomycin were determined by agar dilution method and E-test (BioMerieux, SA) according to the CLSI's (2006) guidelines [14] and manufacturer's recommendations, respectively. E. faecalis ATCC 29212 was used as a quality control strain on every occasion of susceptibility testing.

\section{Detection of Virulence Genes by PCR}

DNA extraction was performed by boiling method as described previously [15] and then by commercial kit $\left(\mathrm{DNG}^{\mathrm{TM}}\right.$-Plus, CinnaGen, Iran). Multiplex PCR was performed on all enterococcal isolates for the detection of virulence determinants with specific primers for each gene (Table 1) with some modification on Vankerckhoven's protocol [16]. Briefly, first $25 \mu 1$ master mix containing $2.5 \mu 1$ of bacterial suspension, $15 \mathrm{pM}$ of each primers for asa 1 and gelE and $30 \mathrm{pM}$ for esp, 1X PCR buffer, $2.0 \mathrm{mM} \mathrm{MgCl}_{2}$, $0.2 \mathrm{mM}$ each deoxynucleotide triphosphate (dATP, dCTP,

Table 1. Primers used in this Study

\begin{tabular}{|c|c|c|c|}
\hline Genes & Sequence (5' to 3 ') & Size(bp) & References \\
\hline asal & $\begin{array}{l}\text { F1: GCACGCTATTACGAACTATGA } \\
\text { R1: TAAGAAAGAACATCACCACGA }\end{array}$ & 375 & [15] \\
\hline gelE & $\begin{array}{l}\text { F2: TATGACAATGCTTTTTGGGAT } \\
\text { R2: AGATGCACCCGAAATAATATA }\end{array}$ & 213 & [15] \\
\hline esp & $\begin{array}{l}\text { F7: AGATTTCATCTTTGATTCTTGG } \\
\text { R7: AATTGATTCTTTAGCATCTGG }\end{array}$ & 510 & [15] \\
\hline cpd & $\begin{array}{l}\text { F8: TGGTGGGTTATTTTTCAATTC } \\
\text { R8: TACGGCTCTGGCTTACTA }\end{array}$ & 782 & [29] \\
\hline ace & $\begin{array}{l}\text { F9: GGAATGACCGAGAACGATGGC } \\
\text { R9: GCTTGATGTTGGCCTGCTTCCG }\end{array}$ & 616 & [14] \\
\hline $\operatorname{van} A$ & $\begin{array}{l}\text { F14-CATGAATAGAATAAAAGTTGCAATA } \\
\text { R14-CCCCTTTAACGCTAATACGATCAA }\end{array}$ & 1030 & [12] \\
\hline $\operatorname{van} B$ & $\begin{array}{l}\text { F15-GTGACAAACCGGAGGCGAGGA } \\
\text { R15-CCGCCATCCTCCTGCAAAAAA }\end{array}$ & 433 & [12] \\
\hline E. faecalis & $\begin{array}{l}\text { F16-ATCAAGTACAGTTAGTCTTTATTAG } \\
\text { R16-ACGATTCAAAGCTAACTGAATCAGT }\end{array}$ & 941 & {$[12]$} \\
\hline E. faecium & $\begin{array}{l}\text { F17-TTGAGGCAGACCAGATTGACG } \\
\text { R17-TATGACAGCGACTCCGATTCC }\end{array}$ & 658 & [12] \\
\hline
\end{tabular}


dGTP, and dTTP) and $2.5 \mathrm{U}$ of Taq DNA polymerase (CinnaGen, Iran). The second PCR mixture contained $10 \mathrm{pM}$ of each primer for $c p d$ and $4 \mathrm{pM}$ for ace, $1.5 \mathrm{mM} \mathrm{MgCl}_{2}$ and additional rest of reagents mentioned in first master mix. Reactions for both mixtures were done on a thermal cycler (ASTEC-Japan) with an initial denaturation at $95^{\circ} \mathrm{C}$ for 10 min, 30 cycles of amplification (denaturation at $94^{\circ} \mathrm{C}$ for 1 min, annealing at $56^{\circ} \mathrm{C}$ for $1 \mathrm{~min}$, and extension at $72^{\circ} \mathrm{C}$ for $1 \mathrm{~min}$ ), and a final extension at $72^{\circ} \mathrm{C}$ for $10 \mathrm{~min}$.

Amplicons were analyzed on a $1.5 \%$ agarose gel and a 100-bp DNA ladder was used as the molecular size marker. The gels were stained with ethidium bromide and photographed under UV light. Each PCR assay was accompanied with a negative control, containing all of the reagents without template DNA.

\section{Statistical Analysis}

Data were analyzed statistically using chi-square test and difference was considered significant at $p<0.05$ by SPSS software (version 18).

\section{RESULTS}

Most of VREs were isolated from intensive care units (ICUs) [16(33.3\%)], nephrology [10(20.8\%)] and internal [8(16.7\%)] wards. Among VRE strains, thirty- five $E$. faecium harboured vanA gene and all of them revealed $\mathrm{MICs} \geq 256 \mu \mathrm{g} / \mathrm{ml}$, except one $(\mathrm{MIC}=8 \mu \mathrm{g} / \mathrm{ml})$. Five vanA positive isolates did not show any studied virulence determinants. On the other hand, 3 E. faecium isolates carried $v a n B$ gene with MICs $<4 \mu \mathrm{g} / \mathrm{ml}$ and also, they were negative for all virulence determinants tested. However, VREfm isolates were found with the esp gene (71.05\%).

All E. faecalis showed MICs $\geq 256 \mu \mathrm{g} / \mathrm{ml}$ and 8 isolates carried vanA gene while, in the two strains, neither vanA nor $v a n B$ gene were detected.

In comparison to $E$. faecium, vancomycin resistant $E$. faecalis strains were furnished with diverse combinations of virulence genes include: 4 strains presenting asal, gelE, ace and $c p d ; 4$ strains with asal, gelE and $c p d ; 1$ strain showed gelE, ace and cpd and another one displayed gelE and cpd. Among virulence genes studied, concomitant occurrence of gelE and cpd in all E. faecalis isolates was significant $(p<0.001)$. Distribution of virulence genes among vancomycin resistant E. faecalis and E. faecium are shown in Table 2.

Table 2. Distribution of Virulence Genes among Vancomycin Resistant $E$. faecalis and $E$. faecium Isolates

\begin{tabular}{|l|ll|c|}
\hline \multirow{2}{*}{$\begin{array}{l}\text { Virulence } \\
\text { Genes }\end{array}$} & \multicolumn{2}{|c|}{ Vancomycin Resistant } & \multirow{2}{*}{$\begin{array}{c}\text { Total } \\
(\mathrm{N}=48)\end{array}$} \\
\cline { 2 - 3 } & $\begin{array}{l}\text { E. faecalis } \\
(\mathrm{N}=10)\end{array}$ & $\begin{array}{l}\text { E. faecium } \\
(\mathrm{N}=38)\end{array}$ & \\
\hline \hline gelE & $10(100)$ & $3(7.89)$ & $13(27.08)$ \\
asa1 & $8(80)$ & $3(7.89)$ & $11(22.91)$ \\
cpd & $10(100)$ & $1(2.63)$ & $11(22.91)$ \\
ace & $5(50)$ & $1(2.63)$ & $6(12.5)$ \\
esp & $0(0)$ & $27(71.05)$ & $27(56.25)$ \\
\hline
\end{tabular}

\section{DISCUSSION}

This study investigated prevalence of virulence factors in vancomycin resistant enterococci. The majority of VREs were E. faecium (38 out of 48 VREs). Similar enhancement in the prevalence of VRE, especially $E$. faecium has been noticed earlier in several studies from different countries [17-19]. This increase has been attributed mainly to the occurrence and spread of vanA and vanB positive VRE, which exhibited some virulence factors such as Esp (esp), cytolysin (cyl), hyaluronidase (hyl) [10]. In comparison among various sources of Enterococci, the same as clinical samples, farm animals, water and food products, isolates from clinical specimens have been attributed to have the highest virulence factors [20, 21]. In this study, E. faecalis and $E$. faecium strains show significantly different patterns in the incidence of virulence determinants. Similar to study of Eaton et al., (2001), in our study, all E. faecalis strains harbored multiple virulence determinants.

The aggregation substance is a pheromone-inducible surface protein encoded by asal gene involved in adherence to eukaryotic cell [22], which may increase the hydrophobicity of the enterococcal cell surface that may delay or prevent fusion with lysosomal vesicles [23], cell aggregation and conjugation [24]. Various reports are available for the prevalence of asal in enterococcal isolates obtained from different sources. In this study 8 out of 10 E. faecalis harbored asal gene and majority (62.5\%) of them were being isolated from urine specimen. Waar et al., (2002) reported high prevalence of asal in E. faecalis isolates from liver transplant and septicemic patients and assumed that asal might be associated with infection [25]. Baldassarri et al., [26] indicated presence of this gene in seven out of $11 \mathrm{E}$. faecalis from endocarditis, with only one strain being van $\mathrm{A}$ positive. The present study also revealed this gene in 3 (7.89 $\%)$ VREfm isolates from UTI, whereas other studies did not find asal in E. faecium [16, 27, 28]. A much higher incidence (13\%) has been reported by Elsner et al., [29] in clinical E. faecium isolated from blood culture. A study on food and medical isolates of enterococci showed the asal gene was always associated with the presence of pheromone determinants (cpd, cob, $c c f$ and $c a d$ ) and only detected in E. faecalis [30]. Abriouel et al., (2008) reported high prevalence of $c p d(89.7 \%)$ determinant in comparison of aggregation substance $(58.97 \%)$ in clinical E. faecalis [28]. Similarly, we found the cpd gene in all VREfs, of them $80 \%$ were also asal positive $(p<0.001)$. Meanwhile, we could find $c p d$ in one VREfm, suggests that it is probably not associated with virulence in this species. The presence of sex pheromone determinant in E. faecium was reported earlier [31].

Gelatinase encoded by gelE is an extracellular metalloendopeptidase that hydrolyzes gelatin, collagen, hemoglobin, and other bioactive compounds [32]. Sabia et al., (2008) reported gelE gene in $19(70 \%)$ out of 27 VRE strains; all E. faecalis and 5 out of 7 E. faecium carried the gelE [33]. In accordance, we detected gelE gene in all VREfs and $7.9 \%$ of VREfm. In fact, among virulence genes investigated, concomitant occurrence of gelE and $c p d$ in E. faecalis isolates was found significant $(p<0.001)$. In contrast, some studies did not find gelE gene in any $E$. 
faecium isolates [34] while, other researchers reported different incidence for mentioned gene in clinical isolates $[11,27]$. Silent form of this gene was reported in E. faecium isolates [30, 35].

The ace gene, which codes for a putative protein with characteristics similar to a collagen-binding protein of Staphylococcus aureus [36] has been identified more frequently in E. faecalis isolates [27, 37]. Abriouel et al., (2008) reported higher incidence of ace gene $(>80 \%)$ in clinical isolates in comparison to much lower incidence or even absence in isolates obtained from vegetable foods, water and soil [28]. The present study revealed the ace gene in $50 \%$ of E. faecalis and only in one E. faecium. All ace positive isolates obtained from urine (UTI) and isolates from other sources were negative for this gene. Lebreton et al., (2009) suggested that Ace may be a valuable drug target against human UTI. Low incidence or absence of the ace in clinical E. faecium have been reported in some studies $[11,27]$ but it is unlikely to contribute significantly to virulence.

Esp protein encoded by esp gene assumed to play a role in the primary surface attachment, contributing to colonization and persistence on urinary tract and biofilm formation $[38,39]$. The $e s p$ is one of the disputed virulence elements that found on a pathogenicity island of both $E$. faecalis and E. faecium [40, 41].

Although, an earlier study demonstrated esp gene only in E. faecalis isolates [42] and other available data indicated that the esp gene was common in E. faecalis [15] however, a study on the food and medical isolates depicted an increasing incidence of esp in clinical E. faecium isolates than $E$. faecalis [30] and an European investigation proposed, proposed only this gene for virulence among this species [16]. Camargo et al., (2006) demonstrated that esp (56\%) was restricted to VREfm and not found in vancomycin sensitive E. faecium [43]. Vankerckhoven et al., [16] surveyed virulence genes in European hospitals and found higher incidence of esp in the clinical VREfm isolates. In accordance with these investigations, in our study esp was the most common gene in VREfm $(71.05 \%)$ but not detected in VREfs. Moreover, earlier Van Wamel et al., (2007) demonstrated that Esp expression on the surface of $E$. faecium; dependent to growth condition, to vary consistently among strains and is quantitatively correlated with initial adherence and biofilm formation [44].

In the present study, three E. faecium isolates with $v a n B$ genotype were susceptible to vancomycin (MIC $<4$ $\mu \mathrm{g} / \mathrm{ml}$ ) and did not carry any of examined virulence determinants. A research conducted on Australian patients with haematological disorders showed high incidence of $e s p$ gene in vancomycin resistant $E$. faecium (vanB positive), but all were negative for asal and gelE [45].

\section{CONCLUSION}

Our data indicate a high prevalence of E. faecium harboring vancomycin resistance with vanA genotype. In addition, finding of 3 E. faecium with $\operatorname{vanB}$ genotype, but sensitive to vancomycin, suggest application of both phenotypic and genotypic methods for screening
VRE strains since using them in single may lead to misidentification.

VREfs possessed four distinctive patterns of virulence factors and the gelE gene was always associated with the presence of pheromone determinant $(c p d)$ and these combinations may associate with increased virulence. Interestingly, esp was not found in any of VREfs strains.

On the other hand, the $e s p$ was the dominant determinant among E. faecium strains. Finding of esp gene in high incidence among E. faecium, but not in E. faecalis, may indicate the role of this gene in high prevalence of VREfm in hospitals environments. Although the gelE, $c p d$, asal and ace genes were found in less frequencies, but there is a trend of increasing levels of virulence genes other than esp among $E$. faecium strains.

Meanwhile, in 8 of VREfm ( $3 v a n B^{+}$and five $\left.v a n A^{+}\right)$ none of these genes was present, it was concluded that other genes may be also important in the pathogensis of VRE isolates.

However, further investigation is required to evaluate the association of these virulent determinants with occurrence of an infection by VREs in more number of isolates.

\section{CONFLICT OF INTERESTS}

Declared none.

\section{ABBREVIATIONS}

$\begin{array}{ll}\text { Ace } & =\text { Collagen binding protein } \\ \text { Asa1 } & =\text { Aggregation substance } \\ \text { ATCC } & \text { American type culture collection } \\ \text { CLSI } & =\text { Cinical and Laboratory Standards Institute } \\ \text { Esp } & =\text { Enterococcal surface protein } \\ \text { GelE } & =\text { Gelatinase } \\ \text { MICs } & =\text { Minimum inhibitory concentrations } \\ \text { Min } & =\text { Minutes } \\ \text { VanA } & =\text { D- Ala- D- Lac ligase } \\ \text { vanB } & =\text { D- Ala- D- Lac ligase } \\ \text { VRE } & =\text { Vancomycin resistant Enterococci } \\ \text { VREfm } & =\text { Vancomycin resistant Enterococcus faecium } \\ \text { VREfs } & =\text { Vancomycin resistant Enterococcus faecalis }\end{array}$

\section{ACKNOWLEDGMENT}

This work was supported by Research Center of Infectious Diseases and Tropical Medicine (grant No.89/3), Tabriz University of Medical Sciences, Tabriz, Iran. We wish to thank Dr. Eimaneini, for providing the vanA and van $B$ positive isolates. In addition, we are grateful to Ms. Mitra Nojavan and Ms. Leila Deighani for their assistance in specimen collection and Mr. Ahad Bazmani for his laboratory support in research center.

This work has been done as part of Ph.D thesis (No. 88/4- 4/5) of first author. 


\section{REFERENCES}

[1] Low DE, Keller N, Barth A, Jones RN. Clinical prevalence, antimicrobial susceptibility, and geographic resistance patterns of enterococci: results from the SENTRY Antimicrobial Surveillance Program, 1997-1999. Clin Infect Dis 2001; 32(suppl 2): 133-45.

[2] Cetinkay Y, Falk P, Mayhall CG. Vancomycin-resistant enterococci. Clin Microbiol Rev 2000; 13: 686-707.

[3] Courvalin P. Vancomycin resistance in gram-positive cocci. Clin Infect Dis 2006; 42: S25-S34.

[4] Fisher K, Phillips C. The ecology, epidemiology and virulence of Enterococcus. Microbiology 2009; 155: 1749-57.

[5] Mundy L, Sahm D, Gilmore M. Relationships between enterococcal virulence and antimicrobial resistance. Clin Microbiol Rev 2000; 13: 513-22.

[6] Mascini E, Bonten M. Vancomycin resistant enterococci: consequences for therapy and infection control. Clin Microbiol Infect 2005; 11: 43-56.

[7] Kearns A, Freeman R, Lightfoot N. Nosocomial enterococci: resistance to heat and sodium hypochlorite. J Hosp Infect 1995; 30: 193-9.

[8] Neely AN, Maley MP. Survival of enterococci and staphylococci on hospital fabrics and plastic. J Clin Microbiol 2000; 38: 724-26.

[9] Kayaoglu G, Ørstavik D. Virulence factors of Enterococcus faecalis: relationship to endodontic disease. Crit Rev Oral Biol Med 2004; 15: 308-20.

[10] Klare I, Konstabel C, Mueller-Bertling S, et al. Spread ofampicillin/vancomycin-resistant Enterococcus faecium of the epidemic-virulent clonal complex-17 carrying the genes esp and hyl in German hospitals. Eur Clin Microbiol Infect Dis 2005; 24: 815-25.

[11] Billstrom H, Lund B, Sullivan A, Nord CE. Virulence and antimicrobial resistance in clinical Enterococcus faecium. Int $\mathbf{J}$ Antimicrob Agents 2008; 3: 374-7.

[12] Manero A, Blanch AR. Identification of Enterococcus spp. with a biochemical key. Appl Environ Microbiol 1999; 65: 4425-30.

[13] Kariyama R, Mitsuhata R, Chow JW, Clewell DB, Kumon H. Simple and reliable multiplex PCR assay for surveillance isolates of vancomycin-resistant enterococci. J Clin Microbiol 2000; 38: 3092-5.

[14] CLSI. Performance Standards for Antimicrobial Susceptibility Testing; 16th ed, Informational Supplement M100-S16. Wayne, PA: Cinical and Laboratory Standards Institute 2006.

[15] Creti R, Imperi M, Bertuccini L, et al. Survey for virulence determinants among Enterococcus faecalis isolated from different sources. J Med Microbiol 2004; 53: 13-20.

[16] Vankerckhoven V, Van Autgaerden T, Vael C, et al. Development of a multiplex PCR for the detection of asa1, gelE, cylA, esp, and hyl genes in enterococci and survey for virulence determinants among European hospital isolates of Enterococcus faecium. J Clin Microbiol 2004; 42: 4473-9.

[17] Willems RJL, Bonten MJM. Glycopeptide-resistant enterococci: deciphering virulence, resistance and epidemicity. Curr Opin Infect Dis 2007; 20: 384-90

[18] Bonadio M, Meini M, Tagliaferri E, Gigli C, Vigna A. Enterococcal glycopeptide resistance at an Italian teaching hospital. J Antimicrobl Chemother 2000; 46: 129-31.

[19] Emaneini M, Aligholi M, Aminshahi M. Characterization of glycopeptides, aminoglycosides and macrolide resistance among Enterococcus faecalis and Enterococcus faecium isolates from hospitals in Tehran. Polish J Microbiol 2008; 57: 173-8.

[20] Busani L, Grosso MD, Paladini C, et al. Antimicrobial susceptibility of vancomycin-susceptible and-resistant enterococci isolated in Italy from raw meat products, farm animals, and human infections. Int J food Microbiol 2004; 97: 17-22.

[21] Mannu L, Paba A, Daga E, et al. Comparison of the incidence of virulence determinants and antibiotic resistance between Enterococcus faecium strains of dairy, animal and clinical origin. Int J Food Microbiol 2003; 88: 291-304.

[22] Galli D, Lottspeich F, Wirth R. Sequence analysis of Enterococcus faecalis aggregation substance encoded bythe sex pheromone plasmid pAD1. Mol Microbiol 1990; 4: 895-904.

[23] Eaton TJ, Gasson MJ. A variant enterococcal surface protein Espfm in Enterococcus faecium; distribution among food, commensal, medical, and environmental isolates. FEMS Microbiol Lett 2002; 216: $269-75$.
[24] Koch S, Hufnagel M, Theilacker C, Huebner J. Enterococcal infections: host response, therapeutic, and prophylactic possibilities. Vaccine 2004; 22: 822-30.

[25] Waar K, Muscholl-Silberhorn AB, Willems RJL, Slooff MJH, Harmsen HJM, Degener JE. Genogrouping and incidence of virulence factors of Enterococcus faecalis in liver transplant patients differ from blood culture and fecal isolates. J Infect Dis 2002; 185: 1121-7

[26] Baldassarri L, Creti R, Arciola C, Montanaro L, Venditti M, Di Rosa R. Analysis of virulence factors in cases of enterococcal endocarditis. Clin Microbiol Infect 2004; 10: 1006-8.

[27] Valenzuela AS, Omar NB, Abriouel H, et al. Risk factors in enterococci isolated from foods in Morocco: Determination of antimicrobial resistance and incidence of virulence traits. Food Chem Toxicol 2008; 46: 2648-52

[28] Abriouel H, Omar NB, Molinos AC, et al. Comparative analysis of genetic diversity and incidence of virulence factors and antibiotic resistance among enterococcal populations from raw fruit and vegetable foods, water and soil, and clinical samples. Int J Food Microbiol 2008; 123: 38-49.

[29] Elsner HA, Sobottka I, Mack D, Claussen M, Laufs R, Wirth R. Virulence factors of Enterococcus faecalis and Enterococcus faecium blood culture isolates. Eur J Clin Microbiol Infect Dis 2000; 19: 39-42.

[30] Eaton TJ, Gasson MJ. Molecular screening of Enterococcus virulence determinants and potential for genetic exchange between food and medical isolates. Appl Environ Microbiol 2001; 67: 1628-35

[31] Heaton MP, Discotto LF, Pucci MJ, Handwerger S. Mobilization of vancomycin resistance by transposon-mediated fusion of a VanA plasmid with an Enterococcus faecium sex pheromone-response plasmid. Gene 1996; 171: 9-17.

[32] Su Y, Sulavik M, He P, et al. Nucleotide sequence of the gelatinase gene (gelE) from Enterococcus faecalis subsp. liquefaciens. Infect Immun 1991; 59: 415-20.

[33] Sabia C, De Niederhäusern S, Guerrieri E, et al. Detection of bacteriocin production and virulence traits in vancomycin resistant enterococci of different sources. J Appl Microbiol 2008; 104: 970-9.

[34] Vankerckhoven V, Huys G, Vancanneyt M, et al. Genotypic diversity, antimicrobial resistance and virulence factors of human isolates and probiotic cultures constituting two intraspecific groups in Enterococcus faecium. Appl Environ Microbiol 2008; 74: 4247-55.

[35] Biavasco F, Foglia G, Paoletti C, et al. VanA-type Enterococci from humans, animals and food: Species distribution, population structure, Tn1546-typing and location, and virulence determinants. Appl Environ Microbiol 2007; 73: 3307-19.

[36] Nallapareddy SR, Singh KV, Duh RW, Weinstock GM, Murray BE. Diversity of ace, a gene encoding a microbial surface component recognizing adhesive matrix molecules, from different strains of Enterococcus faecalis and evidence for production of Ace during human infections. Infect Immun 2000; 68: 5210-7.

[37] Cariolato D, Andrighetto C, Lombardi A. Occurrence of virulence factors and antibiotic resistances in Enterococcus faecalis and Enterococcus faecium collected from dairy and human samples in North Italy. Food Control 2008; 19: 886-92.

[38] Toledo-Arana A, Valle J, Solano C, et al. The enterococcal surface protein, Esp, is involved in Enterococcus faecalisbiofilm formation. Appl Environ Microbiol 2001; 67: 4538-45.

[39] Shankar N, Lockatell C, Baghdayan AS, Drachenberg C, Gilmore MS, Johnson DE. Role of Enterococcus faecalis surface protein Esp in the pathogenesis of ascending urinary tractinfection. Infect Immun 2001; 69: 4366-72.

[40] Leavis H, Top J, Shankar N, et al. A novel putative enterococcal pathogenicity island linked to the esp virulence gene of Enterococcus faecium and associated with epidemicity. J Bacteriol 2004; 186: 672-82.

[41] Shankar N, Baghdayan AS, Gilmore MS. Modulation of virulence within a pathogenicity island in vancomycin-resistant Enterococcus faecalis. Nature 2002; 417: 746-50.

[42] Shankar V, Baghdayan AS, Huycke MM, Lindahl G, Gilmore MS Infection-derived Enterococcus faecalis strains are enriched in esp a gene encoding a novel surface protein. Infect Immun 1999; 67: 193-200.

[43] Camargo I, Gilmore M, Darini A. Multilocus sequence typing and analysis of putative virulence factors in vancomycin resistant and 
vancomycin sensitive Enterococcus faecium isolates from Brazil. Clin Microbiol Infect 2006; 12: 1123-30.

[44] Van Wamel WJB, Hendrickx APA, Bonten MJM, et al. Growth condition-dependent Esp expression by Enterococcus faecium affects initial adherence and biofilm formation. Infect Immun 2007; 75: 924-31.
[45] Worth L, Slavin M, Vankerckhoven V, Goossens H, Grabsch E, Thursky K. Virulence determinants in vancomycin-resistant Enterococcus faecium vanB: clonal distribution, prevalence and significance of esp and hyl in Australian patients with haematological disorders. J Hosp Infect 2008; 68: 137-44.

(C) Sharifi et al.; Licensee Bentham Open.

This is an open access article licensed under the terms of the Creative Commons Attribution Non-Commercial License (http://creativecommons.org/licenses/ by-nc/3.0/) which permits unrestricted, non-commercial use, distribution and reproduction in any medium, provided the work is properly cited. 